\title{
Smoking and Health Research
}

National Cancer Institute

\section{Source}

National Cancer Institute. Smoking and Health Research. NCI Thesaurus. Code C15922.

Research focusing on all activities associated with tobacco smoking; concerns factors that influence individuals to start or stop smoking, how these factors differ by age, sex, ethnic group, educational or socioeconomic level, etc. 